\title{
The Role of Liners in Bonding Zirconia to Veneering Porcelain
}

\author{
Aneta Mijoska ${ }^{1}$, Mirjana Popovska ${ }^{2}$, Biljana Kapusevska ${ }^{3}$, Emilija Bajraktarova-Valjakova $^{4}$ \\ ${ }^{1,2,3,4}$ Faculty of Dentistry, University St. Cyril and Methodicus, Majka Tereza po box 17, Skopje 1000 Republic of Macedonia
}

\begin{abstract}
The role of liners in adhesion of zirconia ceramic to veneering porcelain had been tested with in vitro investigation. Twenty four bilayered ceramic specimens were made, and then tested with shear bond strength test (notched edge) to determine the form of separation and the type of fracture. The resulting values for shear strength were calculated and expressed as the strength of the connection (MPa), compared with the control samples without liner. The resulting values of the strength of adhesion vary the interval 36, $03 \pm 15,33 \mathrm{MPa} ; \pm 95,00 \%$ CI: 26.29 to 45.77. The strength of the interface zirconium-ceramic veneers is significantly higher than the minimum force required in conventional metal-ceramic restorations. Thus the application of porcelain liners is a procedure that has a positive impact on shear bond strength.
\end{abstract}

Keywords: liners, zirconia, bonding, veneering porcelain

\section{Introduction}

Modern ceramic materials in dentistry are divided into two large groups: porcelain ceramic for veneering, and ceramics for the core of all-ceramic restorations [1] Zirconium-dioxide as core ceramic material has great application in modern dental prosthodontics [2]. Biocompatibility, chemical stability, high toughness, excellent aesthetics and modern production procedures with CAD-CAM method, are some of the reasons for application of the constructions in all areas of the oral cavity [3]. Mechanical damage usually occurs during the exploitation of all-ceramic constructions in the presence of functional load, with the masticatory processes in the mouth [4]. The most common complication observed in zirconia-based restorations was fracture of the veneering porcelain, manifesting clinically as "chippings" [5]. They manifest as small surface fractures, breaking away of small fragments of porcelain and serious fractures of zirconium core especially in the connector areas. Fractures of the veneering ceramics are very common, but the reasons for their appearance today is not yet clarified [6].

\section{Literature Survey}

Adhesive bonding between two ceramics probably represents the weakest point of these restorations, and has an important role in the damage of the veneering ceramics [7]. In metal-ceramic prosthetic constructions, the lowest adhesion values, according to ISO standards should be higher than $25 \mathrm{MPa}$ [8], while such values for the adhesion in all-ceramic restorations are not established yet .Zirconia surface is inactive and resistant to most conventional methods of bonding [9]. Yet, there are no standard laboratory methods and procedures for its surface treatment. The need for materials that will ensure continuous, physical contact and compensation of inadequate CTE, led to the production of porcelain liners. They represent a ceramic materials that play the role of the opaque layer of the metal-ceramic restorations [10]. The need for understanding the role and importance of porcelain liners for zirconia, led to the goal of the research, to achieve higher strength of adhesion between the core and veneering ceramic.

\section{Material and Method}

This investigation is laboratory in-vitro test, performed to determine the shear strength (Shear Bond Strength Test), according to ISO standards for testing of dental ceramic materials (ISO 29022: 2013 Dentistry-Adhesion-Notchededge shear bond strength Test) [11].

The experiment was performed on the universal testing machine Shimadzu Autograph AGS-X with measuring range $10 \mathrm{KN}$ and speed of $0.001-1000 \mathrm{~mm} / \mathrm{min}$, at the Mechanical Faculty of UKIM in Skopje, in the accredited laboratory for calibration of force and moment of force (Figure 1). The next step was SEM-skening electronic microscopic analysis in the Laboratory for electron microscopy on SEM OXFORD X-ACT.

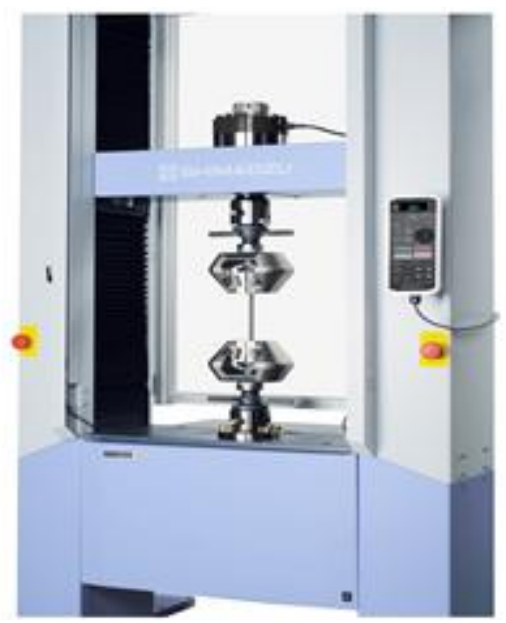

Figure 1: Universal testing machine

\section{Experimental Design}

Experimental zirconia samples were made of zirconia blocks (DeguDent Cercon base 47, Dentsply International Inc, Germany Y-ZTP discs 100x16mm), cut with diamond 


\section{International Journal of Science and Research (IJSR) \\ ISSN (Online): 2319-7064 \\ Index Copernicus Value (2013): 6.14 | Impact Factor (2014): 5.611}

saw in dimensions $10 \times 6 \times 6 \mathrm{~mm}$, and sintered in Cercon heat oven at $1350^{\circ} \mathrm{C}$ for 6 hours. After sintering, the samples got the final strength and dimension with about $20 \%$ shrinkage. Ceramic veneering material (Cercon Ceram Kiss, Degudent Hanau, Germany) was mixed as slurry according to the manufacturer, and placed on the top using special bonding clamp (Ultradent) (Figure 2.).

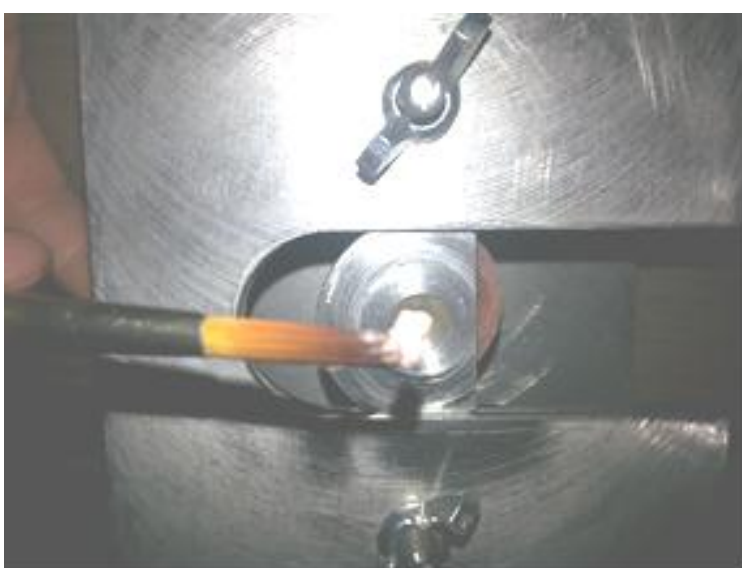

Figure 2: Bonding clamp for applying ceramic material

The samples were then fired in the oven (Programat P310, Ivoclar, Vivadent) with two dentin firings (Table 1), in order to achieve uniform bonding surface of about $3 \mathrm{~mm}$ for all specimens (Figure 3).

Table1: Firing recommendation for Cercon Ceram

\begin{tabular}{|c|c|c|c|c|c|}
\hline $\begin{array}{c}\text { Firing } \\
\text { recommendati } \\
\text { ons }\end{array}$ & $\begin{array}{c}\text { Pre- } \\
\text { heating } \\
\text { temperatu } \\
\text { re }\end{array}$ & $\begin{array}{c}S \\
\text { Dryin } \\
g\end{array}$ & $\begin{array}{c}t \\
\text { Heatin } \\
\text { g rate } \\
\text { t/min }\end{array}$ & $\begin{array}{c}T \\
\text { Firing } \\
\text { temperatu } \\
\text { re }\end{array}$ & $\begin{array}{c}H \\
\text { Vacuu } \\
\text { m time }\end{array}$ \\
\hline liner & 575 & 2.00 & 55 & 970 & 1 \\
\hline First dentin & 450 & 5.00 & 55 & 830 & 1,30 \\
\hline Second dentin & 450 & 5.00 & 55 & 820 & 1,30 \\
\hline
\end{tabular}

Finally all specimens were positioned in acrylic mold for easier handling and performing the test.

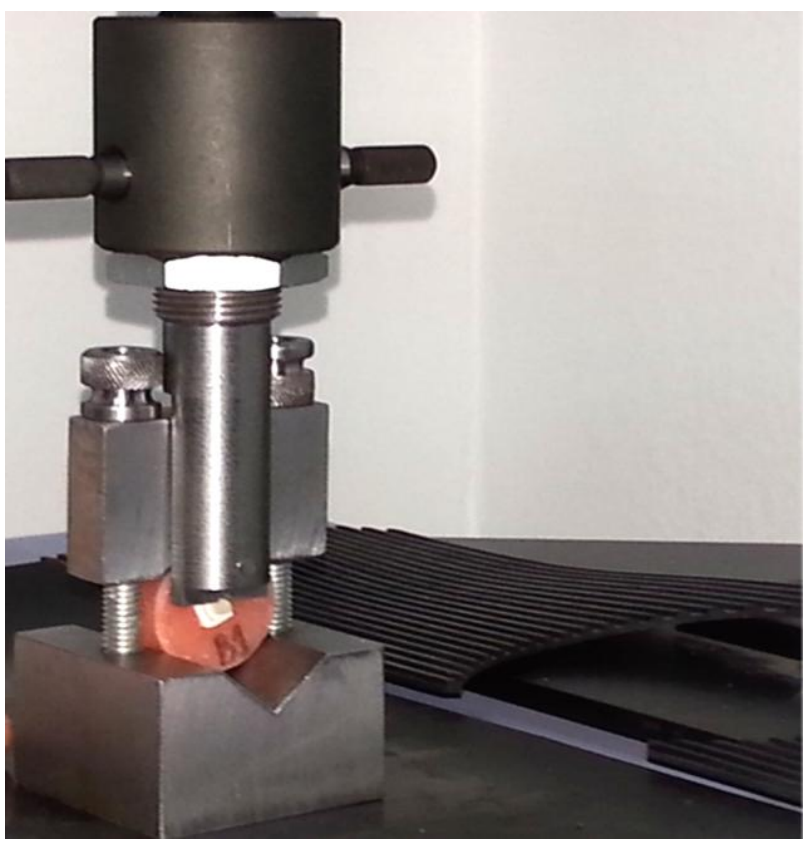

Figure 5: Specimen in acrylic mold

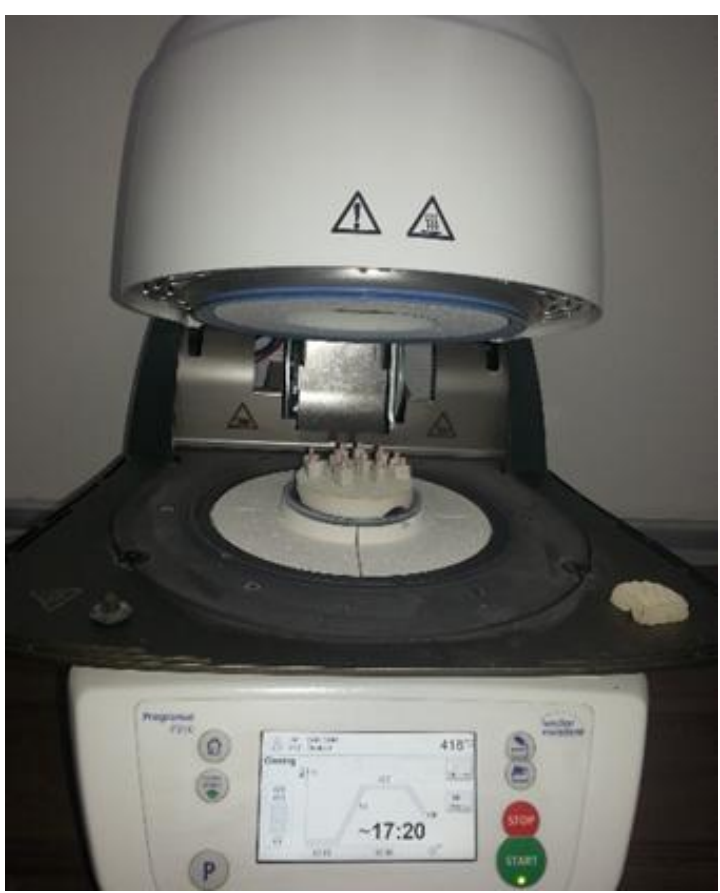

Figure 3: Sintering the specimens in ceramic oven

One group of the specimens had surface treatment with applying ceramic liner Cercon Ceram Kiss Liner (Degudent Hanau, Germany) (Figure 4), and then sintered according the manufacturer. The procedure for applying the liner includes pretreatment of the base zirconia with the procedure of surface sanding (aluminum oxide/100 microns $/ 10 \mathrm{~mm}$ distance/13 sec / $\max 2,8$ bar pressure).

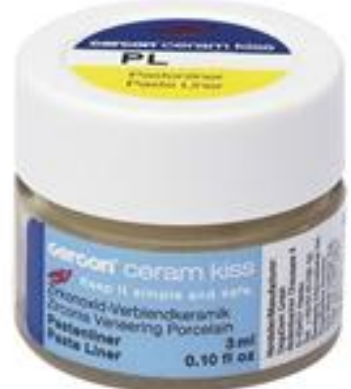

Figure 4: Porcelain liners Cercon Ceram kiss

Two stainless steel adapters were made for the test, one for mounting and fixation of the samples, and the piston with notched edge mounted on the upper part of the machine. The samples were tested, with the piston positioned as close to the bonded interface (Figure 5). The piston was moving vertically down with the speed of 0 , $75 \pm 0,30 \mathrm{~mm} / \mathrm{min}$ until the ceramic interface fractured.

During the testing, the machine was connected to the mobile computing unit to which the registered data of the strength were presented in the form of a graph (Figure 6). 


\section{International Journal of Science and Research (IJSR) ISSN (Online): 2319-7064}

Index Copernicus Value (2013): 6.14 | Impact Factor (2014): 5.611

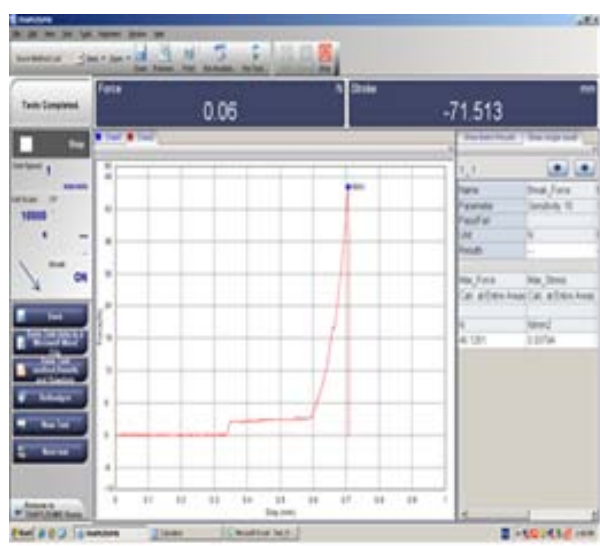

Figure 6: Graphic presentation of the shear force

The results of the breaking force $(\mathrm{N})$ was calculated with the formula for shear bond strength (1)

$\sigma=\mathrm{F} / \mathrm{A}_{\mathrm{b}}$

where $\sigma$ - stress $(\mathrm{MPa}), \mathrm{F}$ - force $(\mathrm{N})$ and $\mathrm{A}_{\mathrm{b}}$ - bonding area $\left(\mathrm{mm}^{2}\right)$. After the completion of testing statistical analysis of data was performed by statistical program
Statistica 7.1 for Windows. Descriptive Statistics, Kolmogorov-Smirnov test; Lilliefors test; Shapiro-Wilks test (p) were used.

\section{Results and Discussion}

Samples B Cercon Ceram Kiss (with surface treatment liner) possess the adhesion force that varies in the range $36,03 \pm 15,33 \mathrm{MPa} ; \pm 95,00 \% \mathrm{CI}: 26.29$ to 45.77 ; minimum value is $18,88 \mathrm{MPa}$ and the maximum value is 62,57 MPa. In the group of samples B1 Cercon Ceram (no surface treatment) the strength of adhesion varies in the interval $29,96 \pm 9,18 \mathrm{MPa}$; $\pm 95,00 \%$, CI: 24.12 to 35.79 ; minimum value is $16,67 \mathrm{MPa}$ and the maximum value is 44,54 $\mathrm{MPa}$. According to descriptive statistical analysis in the group of samples B1 Cercon Ceram (without surface treatment) the strength of the adhesion for $t=-1,18$ and $p>$ $0,05(\mathrm{p}=0,25)$, is slightly lower compared to the strength of adhesion in the group of samples B4 Cercon Ceram (surface treatment liner).

Table 2: Statistical values of tested specimens

\begin{tabular}{|c|c|c|c|c|c|c|}
\hline & \multirow{2}{*}{ group } & Konfidens & Konfidens & & & \\
\cline { 3 - 4 } & no & $95,00 \%$ & $+95,00 \%$ & Min. & Max. & Standard Deviation \\
\hline Cercon Ceram Kiss/ liner B & 12 & 26,29 & 45,77 & 18,88 & 62,57 & 15,33 \\
\hline Cercon Ceram Kiss/control group B1 & 12 & 24,12 & 35,79 & 16,67 & 44,54 & 9,18 \\
\hline
\end{tabular}

Table 3: Shear bond strength values

\begin{tabular}{|c|c|c|c|c|c|c|c|}
\hline \multirow{2}{*}{ Ceramic } & Aver & Aver & & & & & \\
\cline { 2 - 6 } & Group B & Group B1 & t-value & df & p & Stand Deviat. B & Stand Deviat.B1 \\
\hline Cercon Ceram Kiss & 29,96 & 36,03 & 1,18 & 22 & 0,25 & 9,18 & 15,33 \\
\hline
\end{tabular}

After testing, specimens with highest and lowest values for shear bond were scanned, and photographs showed fracture beginning not at the bonded interface zirconia/veneer ceramic but in the ceramic. Each specimen had remained veneering porcelain less than $30 \%$ on the bonded surface. These fractures are called "cohesive" fracture, and they prove that strong bonding caused fracture inside the veneering ceramic (Figure 7).

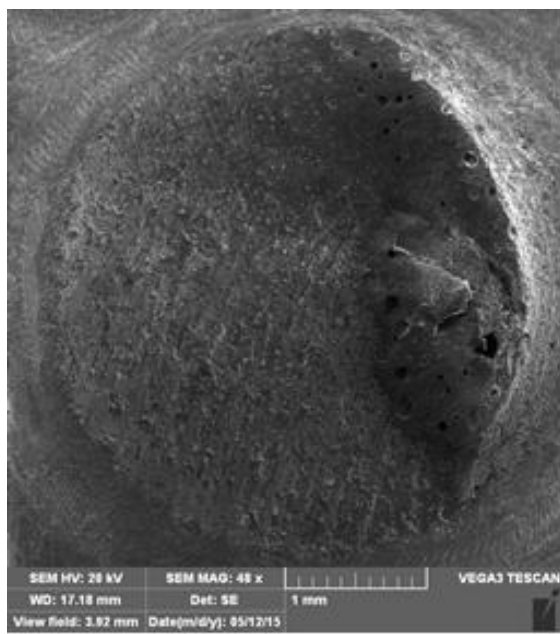

Figure 7: SEM of fractured specimen
Despite improved mechanical properties of zirconia ceramics as a core material for prosthetic restorations, frequent fractures of the veneering layer is most common reason for the failure and replacemeant in a short period of time [12], [13]. There are several theories about the adhesion and the realization of the bonding between the base metal and ceramics for veneering and these are: primary chemical linkage, mechanical, adhesive, Van der Waals forces, compression, interzonal material and others. [14]. One third of the strength of the bonding is due to the wetting force, and two thirds are due to the chemical bond. Brittle all-ceramic restorations cannot be treated as conventional in terms of realization of the bonding between the two layers [15]. The mechanisms linking zirconia and veneering ceramics are not sufficiently clarified, but it is known that the strength of the adhesion in all-ceramic systems is weaker than that which occurs in metal-ceramic systems [16]. The adhesion between the core and veneering ceramics for all-ceramic systems is based on the manner in which the connection at the metalceramic constructions happens [17], [18]. Zirconia is metal and it has chemical bonding with porcelain, although some authors disagree with this [19]. The strength of the adhesion zirconia-porcelain depends on several factors, namely: zirconia surface, residual thermal stress, the coefficient of thermal expansion, the 


\section{International Journal of Science and Research (IJSR) \\ ISSN (Online): 2319-7064 \\ Index Copernicus Value (2013): 6.14 | Impact Factor (2014): 5.611}

appearance of defects in materials, the appearance of defects at the site of adhesion, changes in volume of porcelains, strength and wetting ability [20], [21]. Zirconia surface is inert and common surface treatments like acid and alkaline etching are not efficient. Different surface treatments are proposed for better adhesion. The liners are ceramic material whose function is to provide surface roughness, modification of the color of white zirconium base and improve the mechanism of bonding to porcelain [22]. The lack of nuanced zirconium blocks for long time represented a challenge in terms of aesthetic restorations, but today with the addition of about $2 \%$ glassy phase we got colored blocks. In fact, glassy ceramic liner applied with proper consistency is supposed to represent the pigment layer and "wash bake" process [23]. The thin uniform layer of liner bakes with gradual increase in temperature, which should not be higher than 920-9600 C, and thus allow merging of glassy phase with the base. However some authors in their research suggests that the application of liner has only aesthetic effect, and do not influence the strength of the adhesion between ceramic materials. Application of a thin layer with slow cooling process demonstrated effect of reducing the residual stress in ceramic materials [24].

\section{Conclusion}

The procedure of liner application on the surface of zirconium oxide ceramic, leads to higher forces of the bonding between two ceramic materials and should be an integral part of everyday clinical practice. The liners despite correcting of the color of zirconia, reduce ceramic bulk, and also enable stronger designs that satisfy in posterior regions with high masticatory forces.

\section{References}

[1] JA Griggs, "Recent advances in materials for allceramic restorations", Dent Clin North Am, 51(3) pp. 713-27, 2007.

[2] PF Manicone, P Rossi Iommetti, L Raffaelli, “An overview of zirconia ceramics: basic properties and clinical applications", J Dent, 35(11), pp. 819-26, 2007.

[3] AJ Raigrodski, GJ Chiche, N Potiket, JL Hochstedler, SE Mohamed, S Billiot, et al, "The efficacy of posterior three-unit zirconium-oxidebased ceramic fixed partial dentalprostheses: a prospective clinical pilot study", J Prosthet Dent, 96(4), pp. 237-44, 2006.

[4] A Sundh, G Sjogren, "A comparison of fracture strength of yttrium-oxide- partiallystabilized zirconia ceramic crowns with varying core thickness, shapes and veneer ceramics", J Oral Rehabil, 31(7), pp. 682-8, 2004.

[5] M. Schmitter, D. Mueller, S. Rues, "Chipping behaviour of all-ceramic crowns with zirconia framework and CAD/CAM manufactured veneer", Journal of Dentistry, 40(2), pp. 154-162, 2012.

[6] M. Guazzato, K. Proos, L. Quach, M.V. Swain, "Strength, reliability and mode of fracture of bilayered porcelain/zirconia (Y-TZP) dental ceramics", Biomaterials, 25, pp. 5045-5052, 2014
[7] V Medić, K Obradović-Djuričić, "Factors influencing bonding fixed restorations". Srp Arh Celok Lek. 136 (5-6), pp. 232-40, 2008.

[8] S Saridag, O Tak, G Alniacik, "Basic properties and types of zirconia: An overview". World J Stomatol, 2 (3), pp. 40-47, 2013.

[9] EE Daou, "The Zirconia Ceramic: Strengths and Weaknesses", The Open Dentistry Journal, 8, pp. 3342, 2014.

[10] HI Yoon , IS Yeo , YJ Yi , SH Kim , JB Lee , JS Han, "Effect of surface treatment and liner material on the adhesion between veneering ceramic and zirconia", J Mech Behav Biomed Mater, 40, pp.36974, 2014.

[11] ISO STANDARD for dental materials 29022:2013 Dentistry-Adhesion-Notched-edge shear bond strength test. ISO/TC 106/SC.

[12] WS Oh, KJ Anusavice,"Effect of connector design on the fracture resistance of all-ceramic fixed partial dentures", J Prosthet Dent, 87, pp. 536-42, 2002.

[13] J Fischer, B Stawarczyk, CHF Hammerle, "Flexural strength of veneering ceramics for zirconia", Journal of dentistry, 36 (5), pp. $316-321,2008$.

[14] M O"zcan,"Fracture reasons in ceramic-fused-tometal restorations", Journal of Oral Rehabilitation. 30, pp. 265-269, 2003.

[15] H.M. Ashkanani, A.J. Raigrodski, B.D. Flinn, H. Heindl, L.A. Mancl, "Flexural and shear strengths of $\mathrm{ZrO} 2$ and a high-noble alloy bonded to their corresponding porcelains", Journal of Prosthetic Dentistry, 100 (4), pp. 274-284, 2008.

[16] International Organization for Standardization. I, "Metal-ceramic dental restorative systems", Organization for Standardization; Geneva: Int., 1999.

[17] A Saito, F Komine, MB Blatz, H Matsumura, "A comparison of bond strength of layered veneering porcelains to zirconia and metal", J Prosthet Dent 104, pp. 247-57, 2010.

[18] F Komine, JR Strub, H Matsumura, "Bonding between layering materials and zirconia frameworks", Japanese Dental Science Review, 48(2), pp.153-161, 2013.

[19] M Kern, EJ Swift, "Bonding to zirconia", J Esthet Restor Dent, 23(2), pp. 71-2, 2011.

[20] MN Aboushelib, CJ Kleverlaan, AJ Feilzer, "Effect of Zirconia Type on Its Bond Strength with Different Veneer Ceramics", Journal Prosthodontics, 17, pp. 401-408, 2008

[21] Z Ozkurt, E Kazazoglu, A Unal , "In vitro evaluation of shear bond strength of veneering ceramics to zirconia”, Dent Mater J, 29 (2), pp. 138-46, 2010.

[22] Alikhasi, Marzieh, Siadat, Hakimeh, Monzavi, Naseri, Ali M, Sheikhzadeh, Seddigheh, "The Effect of Porcelain Veneer and Liner Usage on Microtensile Bond Strength of Cercon Zirconia Ceramics", Journal of Mashhad Dental School, 35 (4), pp. 289, 2011

[23] R. Fouquier, "Zirconia- with or without liner", Dent Tech, Master of the craft 88, pp. 19-28, 2002.

[24] G. Martinez, A. Bautista, LF Pacheco, H Garzon, "Liner Effect on Veneer/Zirconia Bond Strength Using Slow Cooling Protocol," Compendium on 5th 


\section{International Journal of Science and Research (IJSR) \\ ISSN (Online): 2319-7064}

Index Copernicus Value (2013): 6.14 | Impact Factor (2014): 5.611

International congress of adhesive dentistry, (3) 9, pp. 34-35, 2013.

\section{Author Profile}

Aneta Mijoska is specialist in prosthodontics, and works as assistant at the department of fixed prosthodontics at the Faculty for Dentistry at State University St. Cyril and Methodius, Republic of

Macedonia. PhD in dentistry (2015) with topic Evaluation of zirconia bonding to veneering ceramics. 